\title{
INHIBITION OF SHEEP VESICULAR GLAND OXYGENASE \\ BY UNSATURATED FATTY ACIDS FROM SKIN OF \\ ESSENTIAL FATTY ACID DEFICIENT RATS
}

\author{
Vincent A. Ziboh*, Jack Y. Vanderhoek**and William E.M. Lands** \\ *Departments of Dermatology and Biochemistry \\ University of Miami School of Medicine \\ Miami, Florida 33152 (U.S.A.) \\ and \\ **Department of Biological Chemistry \\ The University of Michigan \\ Ann Arbor, Michigan 48104 (U.S.A.)
}

\section{Abstract}

Unsaturated fatty acids present in the lipids of essential fatty acid (EFA)deficient rats were found to inhibit the oxygenase activity of sheep vesicular gland in an instantaneous, reversible manner. However, competitive inhibition by high levels of these acids cannot account fully for the reported loss of prostaglandin synthetic capacity of these EFA-deficient animals. A similar competitive inhibition pattern was observed with several anti-inflammatory drugs tested, whereas others also exhibited a time-dependent destructive effect on the oxygenase of the sheep vesicular gland. The relative effectiveness of these drugs in treating inflammations of the skin paralleled their in vitro effects on the vesicular gland oxygenase.

\section{Acknowledgements}

This investigation was supported in part by grant AM14941-01 of the United States Public Health Service and a research grant from Hoffman-La Roche, Inc., Nutley, New Jersey.

Accepted November 16 


\section{PROSTAGLANDINS}

\section{INTRODUCTION}

Several investigators have reported that the biosynthesis of prostaglandin $\mathrm{E}_{2}\left(\mathrm{PGE}_{2}\right)$ from arachidonic acid could be inhibited by a variety of fatty acids $(1-5)$. Recently, we have also shown that some fatty acids inhibit the biosynthesis of $\mathrm{PGE}_{2}$ from arachidonic acid catalyzed by a high speed particulate from human skin (6). It was observed that the eicosatrienoic acid 20:3 (n-3), exerted a profound inhibitory effect on the biosynthesis of $\mathrm{PGE}_{2}$ from arachidonic acid in the skin. In addition, we have found that different fatty acids present in cellular lipids may inhibit the fatty acid oxygenase of sheep vesicular gland in either of two distinct patterns; an instantaneous, concentration-dependent, reversible effect and a time-dependent non-reversible effect (7). In view of the loss of prostaglandin synthesis accompanied by an accumulation of eicosatrienoic acid 20:3 $(n-9)$ in the skin of essential fatty acid (EFA)-deficient rats ( 8 ), it was of interest to ascertain whether this endogenous abnormal fatty acid would inhibit the oxygenase in a reversible or irreversible manner. This paper describes the effects of eicosatrienoic acid and other unsaturated fatty acids present in the skin of EFAdeficient rats on the oxygenase activity of the sheep vesicular gland, the initial step in the prostaglandin biosynthetic pathway, and compares them with the effects of anti-inflammatory drugs commonly used in the treatment of cutaneous lesions.

\section{MATERIALS AND METHODS}

Sheep vesicular gland acetone powder was generously donated by the Upjohn Company. Triamcinolone acetonide was a gift from E. R. Squibb and Sons, Inc., New Brunswick, New Jersey, WP-32 and BL-2338 were provided by Dr. Hebborn, Westwood-Pharmaceuticals, Inc., Buffalo, New York. Commercial polyunsaturated fatty acids were obtained from the Hormel Institute. Reagents were of analytical grade. Deionized water was used for the preparation of all solutions.

The enzyme used in these studies was prepared by homogenizing $50 \mathrm{mg}$ of an acetone powder (3) prepared from sheep vesicular gland in $1 \mathrm{ml}$ of 1.1M Tris-HC1 (pH 8.5) in a small Dounce ball-type homogenizer. Activation of the vesicular gland oxygenase (9) was accomplished by adding $0.1 \mathrm{M}$ phenol to give a final concentration of $0.67 \mathrm{mM}$ and letting the mixture stand at room temperature for at least $30 \mathrm{~min}$. before use.

Oxygen absorption measurement: Oxygen concentrations were measured on a Yellow Springs Instrument Company Model 53 oxygen monitor equipped with a Model 53 oxygen monitor equipped with a Model 5301 bath assembly. The monitor was attached to a Beckman Model 100502 potentiometric recorder and all readings were made using the os transmittance setting of the recorder. The oxidation of arachidonic acid, 20:4 $(n-6)$, by the phenol-activated oxygenase was determined by measuring oxygen absorption at a constant temperature $30^{\circ} \pm 0.5^{\circ}$. In most experiments, the total volume of the reaction mixture in the sample chamber was $3.0 \mathrm{ml}$ (9). Additions of enzyme preparation and various concentrations of fatty acids and antiinflammatory agents were made through the side of the electrode holder. 
Isolation and purification of eicosatrienoic acid from skin of EFA-deficient rats: Skin specimens were removed from the shaved area of the posterior dorsum from six EFA-deficient rats as reported previously (8). The skin specimens were minced and homogenized in a mixture of chloroform-methanol 2: I (10), with a Polytron (model PT20) homogenizer. The tissue debri was removed by filtration through glass wool. The filtrate was evaporated in a rotary evaporator. The total lipids were transesterified by refluxing under nitrogen with $60 \mathrm{ml}$ of a $5 \%$ solution of $\mathrm{HCl}$ in methanol. The methyl esters were separated by preparative thin layer chromatography on silica gel $\mathrm{G}$. Satisfactory results were obtained by thin layer chromatography $(0.5 \mathrm{~mm})$ prepared from a slurry of $40 \mathrm{~g}$ silica gel in $80 \mathrm{ml}$ of $10 \% \mathrm{AgNO}$ in water. Reference fatty acid methyl esters were applied similarly to other plates and were developed in ether: petroleum ether; benzene $(30: 70: 10)$. The separated compounds were visualized after spraying with $0.2 \%$ ethanolic dichlorofluorescein under ultraviolet light. The silica gel band which corresponded with the reference eicosotrienoate was scraped into a sintered funnel, the fatty acid methyl ester was eluted with a mixture of chloroform: methanol (1:1), and the solvent mixture was evaporated to dryness under a stream of nitrogen. The methyl ester was analyzed for purity by GLC, using an F and M model 402 with a flame ionization detector. Glass columns employed for the isolation of methyl esters of fatty acids from EFA-deficient rats were packed with ethylene-glycol-succinate (EGS) according to Mohrhauer and Holman (11) or 3\% OV-101 silicone copolymer coated on Supelcoport, 80-100 mesh (Supelco, Inc., Bellefonte, Pa.). Authentic methyl ester of eicosatrienoic acid $(20: 3, n-3)$ obtained from the Hormel Institute was used as an internal standard.

Further identification of the isolated eicosatrienoic acid was through the plot of carbon number against log retention time. The equivalent chain length (ECL) of the methyl esters were compared with those published by Hofstetter and Holman (12).

\section{RESULTS AND DISCUSSION}

Previous analysis of fatty acids in the skin of EFA-deficient rats showed marked increases in palmitoleic, oleic and $(n-9)$ eicosatrienoic acids in these tissues (8). The levels of linoleic and arachidonic acids were correspondingly decreased in the skin of these animals. The possibility that the elevation of these monoenoic and eicosatrienoic fatty acids could cause the irreversible loss of the oxygenase was indicated in the decreased synthesis of prostaglandin $E_{2}$ from arachidonic acid by skin (8) and also vesicular glands (13) of the EFA-deficient rats. The present studies have demonstrated that the eicosatrienoic acid, $20: 3(n-9)$ isolated from skin of EFA-deficient rats, was not a substrate for the oxygenase since no oxygen consumption could be detected in control assays without arachidonate $20: 4(n-6)$. 


\section{PROSTAGLANDINS}

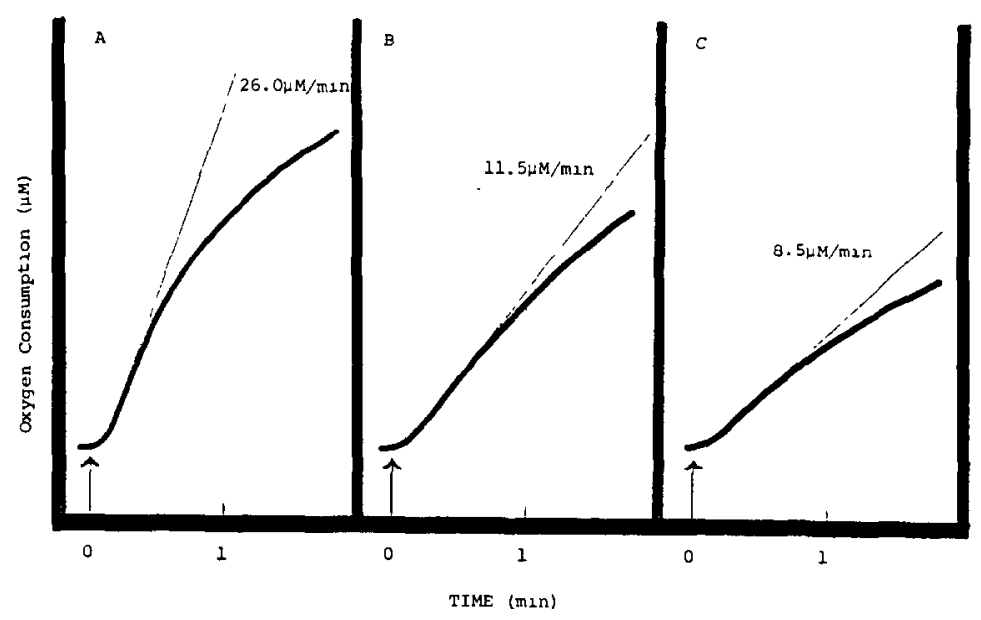

Figure 1. Inhibition of sheep vesicular gland oxygenase by elcosatrienoic acid, 203 $(n-9)$. The phenol-activated preparation (9) was added to incubation mixtures containing $0.67 \mathrm{mM}$ phenol in $0.1 \mathrm{M}$ Tris-HCl buffer $\mathrm{pH} 8.5$. Immediately after the addition of various amounts of elcosatrienoic acid, 20:3 (n-9), arachidonic acid $(20 \mu \mathrm{M}$ final concentration) was added to the incubation chamber to initiate the reaction. The reaction rate was determined from continuous measurements of the decreasing oxygen content. The results from several reaction mixtures are superimposed to illustrate the data obtained. A, O $\mu \underline{M}$ eicosatrienoic acid, B, $90 \mu \mathrm{M}, \mathrm{C}, 135 \mu \mathrm{M}$.

Figure 1 shows that the oxygenation of arachidonic acid in an in vitro system that forms prostaglandins was inhibited by the eicosatrienoic acid, 20:3 $(n-9)$. Prolonged incubation of the oxygenase with this acid prior to assay with 20:4 did not result in any appreciable time-dependent destruction of the enzymic activity as was seen with other substrate analogs (4) or with the substrates themselves (14). A Dixon plot (15) of the data gave an estimated $K_{i}$ value for the $20: 3(n-9)$ of $20 \pm 10 \mathrm{M}$. These results indicate that the $20: 3(n-9)$ fatty acid inhibited the vesicular gland oxygenase in an instantaneous, competitive manner. Competitive inhibition constants of other unsaturated fatty acids present in EFA-deficinet rats are shown on 
TABLE I

INHIBITION OF SHEEP VESICULAR GLAND OXYGENASE BY

UNSATURATED FATTY ACIDS

Phenol-activated acetone powder preparation of sheep vesi-

cular tissue was added into an assay mixture containing $0.67 \mathrm{mM}$

phenol in $0.1 \mathrm{M}$ Tris-HCl buffer, pH 8.5. After tha addition of va-

rious amounts of fatty acids into the incubation mixture, a rachidonic

acid (3-50 $\mu \mathrm{M})$ was added and the reaction rate $(\mu \mathrm{M} / \mathrm{min}=\mathrm{nmole} / \mathrm{ml}$

per min) determined from continuous measurements of oxygen uptake

with the oxygen electrode.

Competitive inhibition constants of the different unsaturated

fatty acids were obtained as described in the text. The figures in

parentheses indicate the number of experiments included.

\begin{tabular}{cc}
\hline FATTY ACID & $\mathrm{K}_{i}(2 \mathrm{M})$ \\
\hline $16: 1(n-7)$ & $105(14)$ \\
$18: 1(n-9)$ & $22(19)$ \\
$20: 3(n-9)$ & $20(8)$ \\
$20: 3(n-6)$ & $5 *(9)$ \\
$20: 3(n-3)$ & $6(19)$ \\
\hline
\end{tabular}

* Since this acid serves as an efficient substrate for the oxygenase, this value represente the apparent $K_{m}$ value for the substrate and enzyme.

Table 1. It can be seen from the data that the inhibitory capacity of $20: 3$ $(n-9)$ is similar to that of $18: 1(n-9)$, with both being better inhibitors than 16:1. However, none of these acids was as effective an inhibitor as the eicosatrienoic $(n-3)$ isomer, noted in the table. On the other hand, the third member of the eicosatrienoic acid family, the $(n-6)$ isomer, is a very efficient substrate for the oxygenase and leads to destruction of the enzyme (14).

Accumulation of large amounts of the $(n-9)$ fatty acids in tissues deficient in the prostaglandin precursors opened the possibility that such high levels may exert an inhibitory effect on any endogenous prostaglandin synthesis in these tissues as the combined unsaturated acids are released from ester precursors. such as phospholipids (16). However, since the (n-7) and (n-9) acids did not cause a progressive loss of the enzyme, their abudance may not fully 


\section{PROSTAGLANDINS}

account for the reported loss of synthetic activity $(8,13)$ of the skin from EFAdeficient animals. It should be noted that the assays that showed the loss of activity were performed in vitro with added unesterified $20: 4$ so that the natural abundance of inhibitors in the esterified precursors could not manifest as marked an effect as when the free acids were derived from the esterified pool.

The effects of various recognized anti-inflammatory agents on the oxidation of $20: 4(n-6)$ by sheep vesicular gland oxygenase were also examined The

TABLE II

THE EFFECTS OF ANTI-INF LAMMATORY AGENTS ON SHEEP VESICULAR GLAND OXYGENASE

Phenol-activated oxygenas $(9)$ was added to an assay mixture containing $0.67 \mathrm{mM}$ phenol and various amounts of the anti-inflammatory agents. After incubation for 1 minute arachidonic acid (20 $\mu \mathrm{M}$ final concentration) was added and the reaction rate determined from continuous measurements of oxygen uptake with an oxygen electrode. The $[1]_{50}$ for each compound is the concentration of inhibitor that caused $50 \%$ inhibition.

\begin{tabular}{lc}
\hline \multicolumn{1}{c}{ AGENTS } & {[]$_{50} \mu \mathrm{M}$} \\
\hline Indomethacin & 9,0 \\
Acetylsalicylic Acid & 7,500 \\
Chloroquine & 61 \\
Guldthiomalate & 49 \\
BL-2338 & 0.8 \\
WP-32 & 1.1
\end{tabular}

concentrations of these compounds that gave $50 \%$ inhibition of the oxygenase are shown in Table 2. Goldthiomalate and BL-2338, were found to inhibit oxygenase activity first in an instantaneous, concentration-dependent manner, 


\section{PROSTAGLANDINS}

and continued pre-incubation of the oxygenase with these compounds, as with indomethacin and acetylsalicylic acid resulted in a time-dependent destruction of the vesicular gland sheep oxygenase. On the other hand, chloroquine, a potent anti-inflammatory agent, and WP-32 inhibited the oxygenase only in an instantaneous concentration-dependent manner. It is interesting to note that the relative effectiveness of these drugs in treating inflammations of the skin (17-19), parallels their in vitro effects with the vesicular gland oxygenase. Apparently, there are major similarities between the fatty acid oxygenase that lead to prostaglandin formation in the two tissues. Hydrocortisone and Triamcinolone acetonide at concentrations up to $132 \mathrm{M}$ were found not to exert appreciable effects on the oxidation of $20: 4(n-6)$ by sheep vesicular gland oxygenase. It is unlikely, therefore, that the therapeutic effectiveness of these two potent anti-inflammatory steroids involve the inhibition of prostaglandin biosynthesis. Other possible mechanisms for their action have been suggested by Willis et al. (20).

\section{REFERENCES}

1. Pace-Asciak C. and Wolfe, L.S. (1968) Biochem. Biophys. Acta. $152,784-787$.

2. Nugteren, D.H. (1970) Biochim. Biophys. Acta 210, 171-176.

3. Wallach, D.P. and Daniels, E.G. (1971) Biochim. Biophys. Acta. $231,445-457$.

4. Vanderhoek, J.Y. and Lands, W.E.M. (1973) Biochim. Biophys. Acta 296, 374-381.

5. Ahern, D.G. and Downing, D.T. (1970) Biochim. Biophys. Acta. $210,456-461$.

6. Ziboh, V.A. (1973) J. Lipid Res. 14, 377-384.

7. Lands, W.E.M., Le'Tellier, P.R., Rome, L.H., Vanderhoek, J.Y. (1973) Advances in the Biosciences 9, 15-28.

8. Ziboh, V.A. and Hsia, S.L. (19/2) J. Lipid Res. 13, 458-467.

9. Smith, W.L. and Lands, W.E.M. (1972) Biochemistry 11, $3276-3285$.

10. Folch, J., Lees, M. and Sloane Stanley, G.H. (1957) J. Biol. Chem. 226, 497-509.

11. Mohrhauer, H, and Holman, R.T. (1962) J. Lipid Res, 4, 151-159.

12. Hofstetter, H.H., Sen. N. and Holman, R.T. (1965) J. Am. Oil Chem. Soc. 42, 537-544.

13. Tan, W.C. and Privett, O.S. (1973) Biochim. Biophys. Acta. 296, 586-592. 


\section{PROSTAGLANDINS}

14. Lands, W.E.M., Lee, R. and Smith, W. (1971) Ann. N.Y. Acad. 180, 107-122.

15. Dixon, M. and Webb, E.C. (1964) Enzymes, 2nd edition p 328, Academic Press, New York.

16. Lands, W.E.M. and Samuelsson, B. (1968) Biochim, Biophys. Acta $164,426-429$

17. Rothfield, N.F . and March, C.H. (1971) In Dermatology in Internal Medicine, Fitzpatrick, T.B. et. al. (editors): McGray-Hill Book Company, p. 1501.

18. Penneys, N.S., Indgin, S., Frost, P. Arch. Drmatol. In Press.

19. Freyberg, R.H., Ziff, M., Baum, J. (1972) In Gold Therapy for Rheumatoid Arthritis. Hollander, J.L. and McCarty, D.J. (editors): Philadelphia Lea and Febiger, pp. 445-482.

20. Willis, A.L., Davison, P., Ramwell, P.W., Brocklehurst, W.E. and Smith, B. Prostaglandins in Cellular Biology, Alza Conf. Series (1972), Vol, 1, 227-251. 